Research article

\title{
Optimization of a thermal hydrolysis process for sludge pre-treatment
}

\author{
I. Sapkaite ${ }^{\text {a }}$, E. Barrado ${ }^{\text {b }}$, F. Fdz-Polanco ${ }^{\text {a }}$, S.I. Pérez-Elvira ${ }^{\text {a, * }}$ \\ ${ }^{a}$ Department of Chemical Engineering and Environmental Technology, University of Valladolid, Spain \\ ${ }^{\mathrm{b}}$ Department of Analytical Chemistry, University of Valladolid, Spain
}

\section{A R T I C L E I N F O}

\section{Article history:}

Received 25 October 2016

Received in revised form

13 January 2017

Accepted 19 January 2017

\section{Keywords:}

Waste activated sludge

Methane production

Response surface methodology

Solubilisation

Thermal hydrolysis

\begin{abstract}
A B S T R A C T
At industrial scale, thermal hydrolysis is the most used process to enhance biodegradability of the sludge produced in wastewater treatment plants. Through statistically guided Box-Behnken experimental design, the present study analyses the effect of $\mathrm{TH}$ as pre-treatment applied to activated sludge. The selected process variables were temperature $\left(130-180{ }^{\circ} \mathrm{C}\right)$, time $(5-50 \mathrm{~min})$ and decompression mode (slow or steam-explosion effect), and the parameters evaluated were sludge solubilisation and methane production by anaerobic digestion. A quadratic polynomial model was generated to compare the process performance for the 15 different combinations of operation conditions by modifying the process variables evaluated. The statistical analysis performed exhibited that methane production and solubility were significantly affected by pre-treatment time and temperature. During high intensity pre-treatment (high temperature and long times), the solubility increased sharply while the methane production exhibited the opposite behaviour, indicating the formation of some soluble but non-biodegradable materials. Therefore, solubilisation is not a reliable parameter to quantify the efficiency of a thermal hydrolysis pre-treatment, since it is not directly related to methane production. Based on the operational parameters optimization, the estimated optimal thermal hydrolysis conditions to enhance of sewage sludge digestion were: $140-170{ }^{\circ} \mathrm{C}$ heating temperature, $5-35 \mathrm{~min}$ residence time, and one sudden decompression.
\end{abstract}

๑) 2017 Elsevier Ltd. All rights reserved.

\section{Introduction}

In a conventional wastewater treatment plant, up to $60 \%$ of chemical oxygen demand (COD) initially present in the influent is recovered as a mixture of primary and activated sludge (Garrido et al., 2013). A new perspective is being generated due to the increase of the amount of sewage sludge and its disposal limitation by reason of strict environmental regulations, effective methods of making full use of sludge's rich organic components are on continuing interest (Zhang et al., 2014). Anaerobic digestion still appears as the most suitable method to treat the sludge due to its limited environmental impact, high potential for energy recovery as biogas, and reduction in the amount of biosolids to be disposed (Ariunbaatar et al., 2014). It is well known that for solid wastes the hydrolysis (liquefaction or solubilisation) step is the main rate limiting factor for digestion. The introduction of a physical, chemical or biological pre-treatment step before digestion has

\footnotetext{
* Corresponding author.

E-mail address: sarape@iq.uva.es (S.I. Pérez-Elvira).
}

demonstrated to improve the global kinetics and performance of the process.

On an industrial scale, the thermal hydrolysis represents the most profitable and reliable alternative (Cano et al., 2015). The main drivers for the use of thermal hydrolysis is the better energy balance due to the increase on biogas production and on better quality of the biosolids produced after digestion, both factors positively affect the operational cost of the treatment plant. From a disposal point of view, it is important to note that the hydrolysed sludge is sterilised at elevated temperatures and complies with the Environmental Protection Agency (EPA) requirements for Class A sludge.

Although nowadays developed at industrial scale (Cambi ${ }^{\circledR}$, Biothelys ${ }^{\mathbb{R}}$, Exelys $^{\mathbb{R}}, \mathrm{TPH}^{\mathbb{R}}$, Lysotherm ${ }^{\mathbb{R}}$, Turbotec $\left.{ }^{\mathbb{R}}\right)$, there is no general agreement on the optimum operation conditions.

Two different mechanisms can be applied to hydrolyse the sludge: i) thermal effect based on the single action of elevated temperatures and ii) steam explosion generated by a sudden decompression (Pérez-Elvira et al., 2008).

According to some researches, heating temperature and duration of the thermal pre-treatment depend on the nature of the 
sludge (Ariunbaatar et al., 2014; Appels et al., 2008). The generally accepted operation conditions vary between 150 and $230{ }^{\circ} \mathrm{C}$ temperature, with time ranging from 20 to $60 \mathrm{~min}$. Regarding the steam explosion option, some commercial processes flash the sludge, while other commercial technologies do not use this steam explosion mechanism. There is no bibliographical reference evaluating if flashing or re-flashing (several sudden decompressions) can further enhance the solubilisation of organic matter thereby increasing the methane production. However, the recovery of steam when flashing the sludge can be a clear economic advantage by steam recovery.

The objective of this study was therefore to determine the optimum conditions for thermal hydrolysis of waste activated sludge after studying the combined effect of pre-treatment temperature, time and flash by Response Surface Method (RSM) using the BoxBehnken experimental design (BBD). An optimal combination of factors that maximize methane production is proposed and analyzed.

\section{Materials and methods}

\subsection{Sludge sampling}

The study was performed with a single sample of waste activated sludge (WAS), provided by the municipal waste water treatment plant of Valladolid (Spain). According to Pérez-Elvira et al. (2008), the sludge was thickened without polyelectrolyte to $14 \%$ TS (73\% VS) to perform the study with concentrated sludge, which is the real operation in pre-treatment units.

The anaerobic inoculum for the biochemical methane potential (BMP) tests was sampled from the anaerobic digester in the WWTP treating mixed sludge, and pre-incubated for 2 days at $35^{\circ} \mathrm{C}$ in a thermostated chamber prior to use to activate the microorganisms and to deplete most residual organic matter.

\subsection{Thermal pre-treatment procedure}

The thermal hydrolysis pilot plant operated (Fig. 1) consisted of a $20 \mathrm{~L}$ hydrolysis reactor heated with live steam (12 bars) from a boiler, and connected to an atmospheric flash vessel $(100 \mathrm{~L})$ by a decompression valve. The operation is batch, controlling heating temperature and time. The decompression is also controlled by an automatic decompression valve, that reliefs the reactor pressure slowly (no flashing) or suddenly (in a steam-explosion effect). When the flash takes place, the hydrolysed solids are collected in the flash vessel at atmospheric pressure.

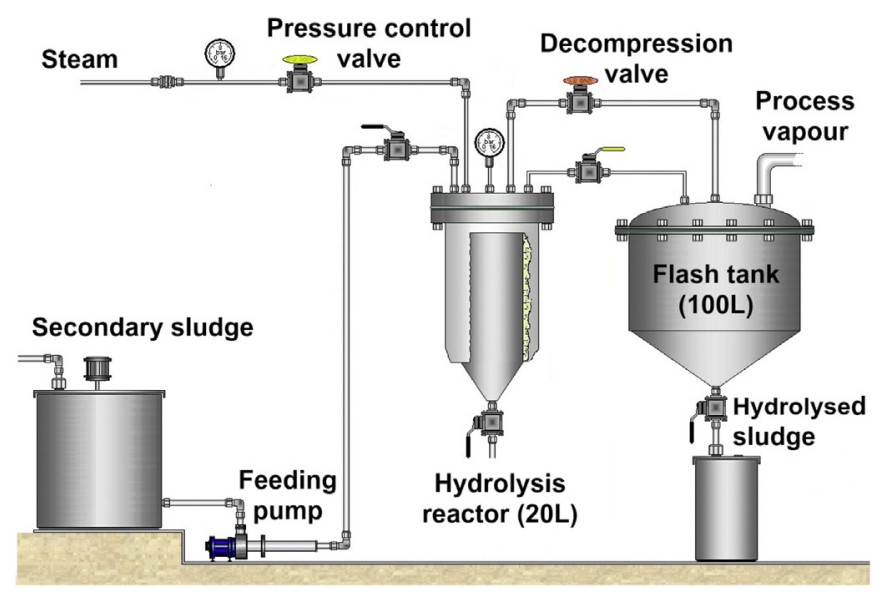

Fig. 1. Thermal pre-treatment system (Fernández-Polanco et al., 2008).

\subsection{Anaerobic digestion tests}

Biochemical methane potential (BMP) tests were performed in triplicate assays using $300 \mathrm{ml}$ serum bottles, filled with $100 \mathrm{ml}$ of a mixture of anaerobic inoculum and the corresponding substrate at a substrate to inoculum ratio (SIR) of $0.5 \mathrm{~g} / \mathrm{g}$ (on volatile solids (VS) basis). In this test, micronutrients and macronutrients were added ensuring no nutritional limitation for optimal function of anaerobic microorganisms. Moreover, $\mathrm{NaHCO}_{3}$ and $\mathrm{Na}_{2} \mathrm{~S}$ were added to provide buffer capacity and avoid aerobic conditions respectively. The methodology used was based on the one suggested by Angelidaki et al. (2009).

The bottles were incubated in a thermostated chamber at $35^{\circ} \mathrm{C}$ in an orbital shaker at $150 \mathrm{rpm} / \mathrm{min}$. Methane production in the BMP tests was determined by periodic measurements of pressure and biogas composition.

\subsection{Analytical methods and performance parameters}

Total solids (TS) and volatile solids (VS) concentrations were determined according to Standard Methods (21st edition, 2005). The soluble phase for chemical oxygen demand (SCOD) was obtained by centrifugation at $5000 \mathrm{rpm}$ for $10 \mathrm{~min}$ and filtration using a $47 \mathrm{~mm}$ hydrophilic Glass Fiber filter with a $0.7 \mu \mathrm{m}$ pore size (AP40). The total COD was obtained by a direct COD analysis.

The pressure in the headspace of the BMP bottles was measured with a pressure sensor PN 5007 (IFM, Germany), and biogas composition was determined using a gas chromatograph coupled to a thermal conductivity detector (Varian CP-3800, USA).

Two performance parameters were calculated: solubilisation and methane production increase.

The solubilisation factor (SB) (Equation (1)) was calculated with respect to the particulate fraction of the chemical oxygen demand (TCOD-SCOD), in contrast to the most of the references (Jung et al., 2015; Kim et al., 2015; Appels et al., 2010) that express this parameter with respect to the total TCOD. This proposed expression is more accurate as the particulate matter is the potentially hydrolysable fraction during the pre-treatment.

$\% S B=\frac{(\mathrm{SCOD} / \mathrm{TCOD})_{\mathrm{TH}}-(\mathrm{SCOD} / \mathrm{TCOD})_{0}}{((\mathrm{TCOD}-\mathrm{SCOD}) / \mathrm{TCOD})_{0}} \times 100$

The specific methane production was evaluated according to Equation (2):

$\mathrm{CH}_{4}=\frac{m L C H_{4}}{g V S_{f e d}}$, at standard conditions $\left(0^{\circ} \mathrm{C}, 1 \mathrm{~atm}\right)$

And the performance of the digestion was calculated by comparing the $\mathrm{CH}_{4}$ values obtained for the treated samples with respect to the untreated WAS, calculating the increase in methane production (Equation (3)):

$\% \mathrm{CH}_{4}=\frac{\left(\mathrm{CH}_{4}\right)_{T H}-\left(\mathrm{CH}_{4}\right)_{0}}{\left(\mathrm{CH}_{4}\right)_{0}} \times 100$

\subsection{Experimental design}

In order to statistically and mathematically determine the optimal conditions of the key operational conditions and the effects of their interactions on the global efficiency of the process, RSM with Box-Behnken experimental Design BBD (Benito-Roman et al., 2013; Jung et al., 2015; Sarat Chandra et al., 2014) was used in this work. 
Three factors at two levels were considered: temperature (130 and $180^{\circ} \mathrm{C}$ ), time ( 5 and $50 \mathrm{~min}$ ) and type of decompression ( 0 and 2 ). The value 0 means that the reactor pressure was relieved slowly, and the hydrolysed sludge was cooled directly without leaving the reactor. Value 2 indicates that the treated sludge was re-flashed twice (just decompressed, not heated twice).

The resulting experimental plan consisted of 15 runs (see Table 1), including three repetitions at the center point of the experimental design.

In order to develop the regression equation, the relationship between the coded values and actual values are described according to the following Equation (4):

$x=\frac{x_{j}-x_{0}}{\Delta x}$

where $\mathrm{x}$ is the coded value, $\mathrm{x}_{\mathrm{j}}$ is the corresponding actual value, $\mathrm{x}_{0}$ is the actual value in the center of the domain, and $\Delta x$ is the increment of $\mathrm{x}_{\mathrm{j}}$ corresponding to a variation of one unit of $\mathrm{x}$.

The relationship between the variables and responses was correlated with a quadratic polynomial Equation (5), that was fitted as follows:

$Y=\beta_{0}+\sum_{j=1}^{k} \beta_{j} X_{j}+\sum_{j=1}^{k} \beta_{j j} X_{j}^{2}+\sum_{i=1}^{k} \sum_{j=1}^{k} \beta_{i j} X_{i} X_{j}$

where $\mathrm{Y}$ is the estimated response variable to be optimized, $\mathrm{Xj}$ are the variables evaluated, $\beta_{0}$ is the constant, $\beta_{\mathrm{j}}$ is the linear coefficient, $\beta_{\mathrm{jj}}$ is a quadratic coefficient and $\beta_{\mathrm{ij}}$ is the interactive coefficient.

An analysis of variance (ANOVA) with $95 \%$ confidence level was done for response variable in order to test the model significance and suitability. The significance of each coefficient was determined using the F-value test, at a 95\% confidence level.

\section{Results and discussion}

\subsection{Experimental set-up and results}

Table 1 summarizes the experimental set-up together with the results obtained for the response variables evaluated (solubilisation and methane production). The CONTROL corresponds to the untreated WAS.

From these values, the effect of heating temperature, hydrolysis time and type of decompression (number of flashes) is analyzed. It

Table 1

Box-Behnken experimental design for the thermal hydrolysis and experimental results.

\begin{tabular}{|c|c|c|c|c|c|c|}
\hline \multirow[t]{2}{*}{ Trials } & \multicolumn{3}{|c|}{ Pre-treatment } & \multicolumn{3}{|l|}{ Results } \\
\hline & $\mathrm{T}\left({ }^{\circ} \mathrm{C}\right)$ & $\mathrm{t}(\min )$ & No. of flashes & SB (\%) & $\mathrm{CH}_{4}(\mathrm{~mL} / \mathrm{gVS})$ & $\Delta \mathrm{CH}_{4}(\%)$ \\
\hline CONTROL & - & - & - & 0 & 220 & - \\
\hline TH-1 & 150 & 50 & 0 & $40 \%$ & 318 & $45 \%$ \\
\hline TH-2 & 130 & 50 & 1 & $34 \%$ & 320 & $45 \%$ \\
\hline TH-3 & 130 & 5 & 1 & $30 \%$ & 316 & $44 \%$ \\
\hline TH-4 & 180 & 30 & 2 & $39 \%$ & 339 & $54 \%$ \\
\hline TH-5 & 150 & 5 & 2 & $31 \%$ & 312 & $42 \%$ \\
\hline TH-6 & 180 & 5 & 1 & $39 \%$ & 325 & $48 \%$ \\
\hline $\mathrm{TH}-7$ & 180 & 50 & 1 & $39 \%$ & 340 & $55 \%$ \\
\hline TH-8 & 150 & 30 & 1 & $36 \%$ & 336 & $53 \%$ \\
\hline TH-9 & 150 & 30 & 1 & $35 \%$ & 361 & $64 \%$ \\
\hline TH-10 & 150 & 30 & 1 & $37 \%$ & 378 & $72 \%$ \\
\hline TH-11 & 180 & 30 & 0 & $41 \%$ & 312 & $42 \%$ \\
\hline TH-12 & 150 & 50 & 2 & $38 \%$ & 335 & $52 \%$ \\
\hline TH-13 & 150 & 5 & 0 & $31 \%$ & 300 & $36 \%$ \\
\hline TH-14 & 130 & 30 & 0 & $33 \%$ & 276 & $25 \%$ \\
\hline TH-15 & 130 & 30 & 2 & $33 \%$ & 296 & $35 \%$ \\
\hline
\end{tabular}

can be noticed that all the pre-treatments evaluated increase the solubilisation and the methane production with respect to the untreated WAS. The results range between 30 and $41 \%$ solubilisation increase and $25-72 \%$ increase in methane production. However, and as will be analyzed, no direct correlation was observed between both responses.

\subsection{Effect of $T H$ variables on the WAS solubilisation}

Fig. 2 represents graphically the influence of the three variables on the waste activated sludge solubilisation. The results clearly exhibit that the increase in sludge solubility is mainly affected by temperature and time, in a rather linear trend: solubilisation is enhanced as the pre-treatment temperature and time increase. The maximum increase in soluble COD is therefore obtained in the most extreme operating conditions ( $180{ }^{\circ} \mathrm{C}$ and 50 min heating).

On the other hand, the decompression effect can be considered negligible.

From the analysis of variance evaluation, presented in Table 2, the obtained coefficients for the linear effect of the temperature (A) and time (B) on the WAS solubility are statistically significant model terms at $95 \%$ confidence level $(p<0.05)$. These results confirm that the temperature and time have a major effect on the sludge solubilisation during the thermal hydrolysis process.

Based on the ANOVA results, Equation (6) was obtained using Equation (5) to fit the experimental data of the sludge solubilisation, being $\mathrm{X}_{1}$ the heating temperature, $\mathrm{X}_{2}$ the hydrolysis time and $\mathrm{X}_{3}$ the decompression mode.

$$
\begin{aligned}
S B(\%)= & 2.29409+0.188889 * X_{1}+0.521411 * X_{2} \\
& +0.111111 * X_{3}-0.00177778 * X_{1} * X_{2} \\
& -0.00204586 * X_{2}^{2}-0.0222222 * X_{2} * X_{3}
\end{aligned}
$$

The model was considered valid because the criteria $\mathrm{r}^{2}>0.8$ was satisfied $\left(r^{2}=0.878\right)$ (Bup Nde et al., 2012). Fig. 3 presents the three-dimensional response surface plot and two dimensional contour plot for the solubilisation factor (\%SB) obtained from Equation (6) for the interaction between temperature and time (sudden decompression in 1 flash was maintained constant).

The graphs reveal that for the evaluated operation ranges of heating temperature and time, the more severe intensity of the thermal pre-treatment (higher temperature and longer times), the higher the solubilisation achieved. These results are in agreement with those obtained by other authors confirming that solubilisation efficiency increase proportional to the temperature rise. Higher pre-treatment temperatures enhance extracellular polymeric substances (EPS) solubilisation and cell lysis (Zhang et al., 2015;

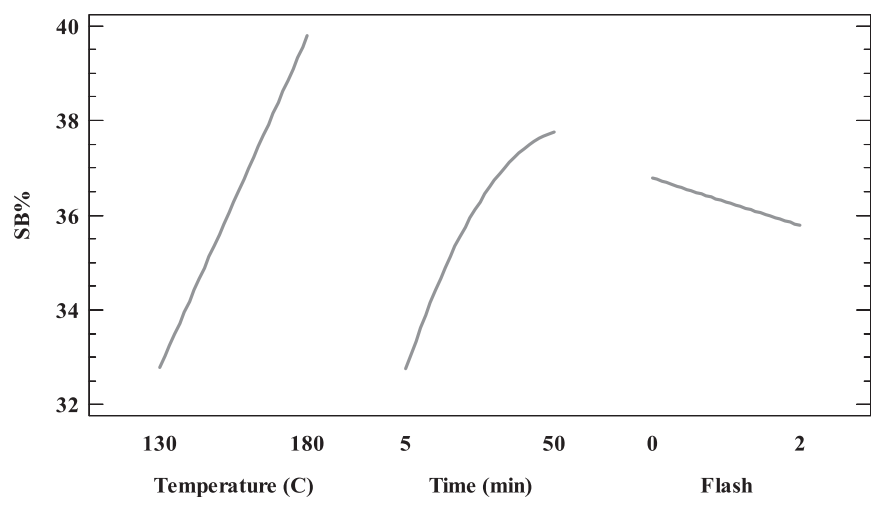

Fig. 2. Influence of the factors evaluated on WAS solubilisation. 
Table 2

ANOVA table for WAS solubility after thermal pre-treatment.

\begin{tabular}{llllll}
\hline Source & Sum of squares & DF & Mean square & F-value & P-value \\
\hline A:Temperature & 98.0 & 1 & 98.0 & 35.75 & 0.0003 \\
B:Time & 50.0 & 1 & 50.0 & 18.24 & 0.0027 \\
C:Flash & 2.0 & 1 & 2.0 & 0.73 & 0.4178 \\
AB & 4.0 & 1 & 4.0 & 1.46 & 0.2615 \\
BB & 4.0 & 1 & 4.0 & 1.46 & 0.2613 \\
BC & 1.0 & 1 & 1.0 & 0.36 & 0.5626 \\
Error total & 21.9 & 8 & 2.7 & & \\
Total (corr.) & 180.9 & 14 & & & \\
\hline
\end{tabular}

Critical value $\left(\mathrm{F}_{0}\right)$ for the F-test: $5.32\left(\mathrm{~F}_{0.05,1,8}\right)$.

Seongyeob et al., 2014; Xue et al., 2015).

It is also interesting to observe that same solubilisation is obtained for the thermal treatment at high temperature - short time, and lower temperature - higher time (i.e.: $36 \% \mathrm{SB}$ at $170{ }^{\circ} \mathrm{C}-10 \mathrm{~min}$ and $140{ }^{\circ} \mathrm{C}-50 \mathrm{~min}$ ).

\subsection{Effect of $T H$ variables on the methane production}

The methane production was compared with the production obtained for the control of untreated sludge $\left(220 \mathrm{ml} \mathrm{CH} 4 / \mathrm{VS}_{\mathrm{fed}}\right)$ following the same evaluation methodology followed for the solubilisation: separate influence of variables, analysis of variance and response plots.

Fig. 4 shows that methane production is affected by all the factors experimentally quantified. In contrast to the results previously obtained for solubilisation, the trend is not linear for the ranges evaluated, and an optimum is obtained for each factor analyzed. First, when temperature increased from $130^{\circ} \mathrm{C}$ to $160^{\circ} \mathrm{C}$, the methane production increased deeper and later started to decrease. The same trend was obtained for the treatment time, exhibiting a decrease in the methane enhancement for values higher than $30 \mathrm{~min}$. Finally, a single sudden flash is the optimum decompression alternative.

Results of the variance analysis are presented in Table 3, exhibiting that coefficients for the linear effect of the temperature (A) and for the squared effects of the temperature (AA) and flash (CC) on methane production are statistically significant model terms at $95 \%$ confidence level $(p<0.05)$. Although not statistically significant, the linear effect of the flash (C) on methane production appears to be more valid than the linear effect of the time (B).

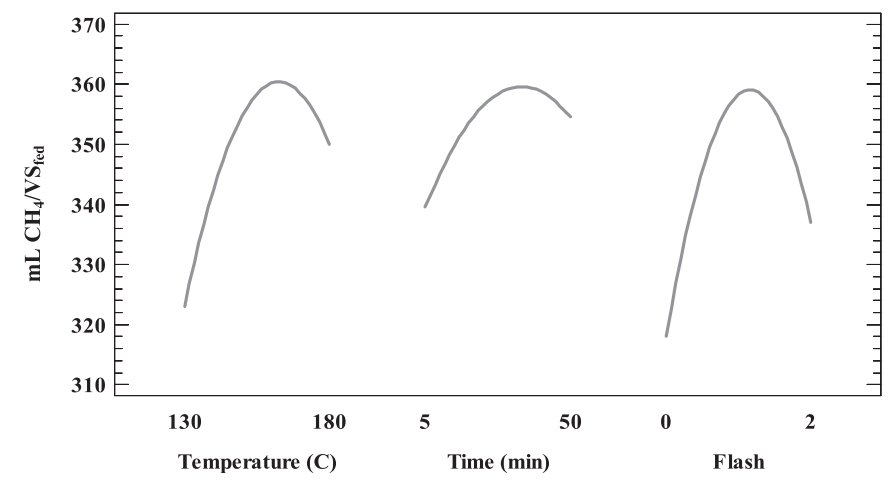

Fig. 4. Influence of the factors evaluated on methane production.

Based on the ANOVA results, Equation (7) was obtained using Equation (5) to fit the experimental data of the methane production, being $\mathrm{X}_{1}$ the heating temperature, $\mathrm{X}_{2}$ the hydrolysis time and $\mathrm{X}_{3}$ the decompression mode.

$$
\begin{aligned}
\mathrm{CH}_{4}\left(\mathrm{~mL} / \mathrm{VS}_{\text {fed }}\right)= & -629.364+11.3487 * X_{1}+1.56008 * X_{2} \\
& +71.0833 * X_{3}-0.0348667 * X_{1}^{2} \\
& -0.0223045 * X_{2}^{2}-30.7917 * X_{3}^{2}
\end{aligned}
$$

The model was considered valid with the same criteria as the previous model for WAS solubilisation, being $r^{2}=0.851$ in this case. The three dimensional response surface plot and two dimensional contour plot shown in Fig. 5 describe the interaction between

Table 3

ANOVA table for the methane production of WAS after thermal pre-treatment.

\begin{tabular}{llllll}
\hline Source & Sum of squares & DF & Mean square & F-value & P-value \\
\hline A:Temperature & 1458 & 1 & 1458 & 8.61 & 0.0189 \\
B:Time & 450 & 1 & 450 & 2.66 & 0.1417 \\
C:Flash & 722 & 1 & 722 & 4.26 & 0.0728 \\
AA & 1753 & 1 & 1753 & 10.35 & 0.0123 \\
BB & 470 & 1 & 470 & 2.78 & 0.1340 \\
CC & 3500 & 1 & 3500 & 20.67 & 0.0019 \\
Error total & 1354 & 8 & 169 & & \\
Total (corr.) & 9098 & 14 & & & \\
\hline
\end{tabular}

Critical value $\left(\mathrm{F}_{0}\right)$ for the F-test: $5.32\left(\mathrm{~F}_{0.05,1,8}\right)$.


Fig. 3. Response surface plot and contour plot showing the effects of temperature and time on WAS solubilisation. 

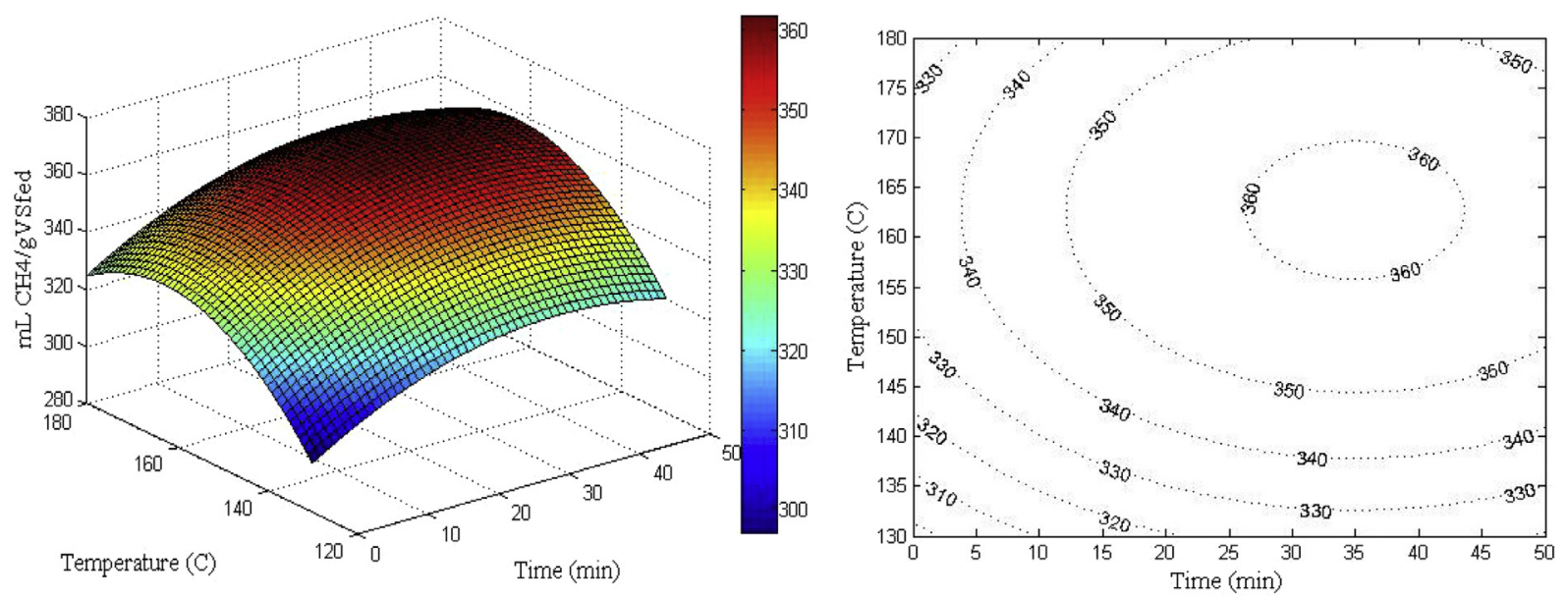

Fig. 5. Response surface plot and contour plot showing the effects of temperature and time on methane production.

thermal pre-treatment temperature and time (again, sudden decompression in 1 flash was maintained constant). These graphs can be used to predict the optimum level of each factor to obtain the maximum expected value for methane production (Sarat Chandra et al., 2014).

Both plots exhibit a peak value for methane production, not corresponding to the maximum values of pre-treatment temperature and time, in contrast to the results obtained for solubilisation. In fact, the negative quadratic effect of temperature and time obtained in Equation (7) implies that, at high severity of the pretreatment, the methane production decreases (Bup Nde et al., 2012). These results agree with those studies reporting inhibition by formation of refractory compounds at high temperatures, generally stated over $170{ }^{\circ} \mathrm{C}$ (Bougrier et al., 2008; Dwyer et al, 2008). This formation of complex substances can also occur at lower temperatures for longer pre-treatment time (Elliot and Mahmood, 2012) as also obtained in Fig. 5.

Fig. 5 also reveals that thermal hydrolysis allows operating in a wide range of conditions reaching similar methane production. In our experiment the highest specific production of $360 \mathrm{mLCH}_{4} /$ $\mathrm{gVS}_{\text {fed }}$ can be obtained in the range $155-175{ }^{\circ} \mathrm{C}$ and $25-45 \mathrm{~min}$. This wide range clearly demonstrates that $\mathrm{TH}$ is a robust process which does not require a very strict and sophisticated operation control system. Expanding the working field until a specific methane productivity $5 \%$ lower than the maximum $\left(340 \mathrm{mLCH}_{4}\right.$ )
$\mathrm{gVS}_{\text {fed }}$ ), the operational range can be extended to $145-170{ }^{\circ} \mathrm{C}$ and 5-45 min, with corresponding savings in energy consumption.

Finally, other relevant technical aspect to be mentioned is that at higher pre-treatment temperature, shorter reaction time is required. The contour plot (Fig. 5) shows that it is possible to achieve identical specific productivity $\left(340-350 \mathrm{mLCH}_{4} / \mathrm{gVS}_{\text {fed }}\right)$ operating at $140-145{ }^{\circ} \mathrm{C}$ during $20-35 \mathrm{~min}$ or at $160-170{ }^{\circ} \mathrm{C}$ for 5-10 min. These results are consistent with those obtained by Zhang et al. (2014) and Hii et al. (2014).

\subsection{Optimization of the $\mathrm{TH}$ process}

The previous discussion of results for solubilisation and methane production show that the evaluated parameters (heating temperature, time and decompression mode) do not influence both responses in the same way, and the trend followed is not the same.

First, the experimental results presented in Table 1 show that solubilisation and methane enhancement do not present a link. For example, a solubilisation around $30 \%$ can lead to a methane increase in the range of $25-44 \%$, and $40 \%$ solubilisation is responsible for $42-55 \%$ methane increase.

Second, based on the models, the optimal values for solubilisation and methane production can be compared. A maximum methane production of $362 \mathrm{mLCH}_{4} / \mathrm{gVS}_{\text {fed }}$ was predicted at the optimum conditions $\left(163^{\circ} \mathrm{C}, 35 \mathrm{~min}\right.$ and $\left.1 \mathrm{flash}\right)$ while a maximum

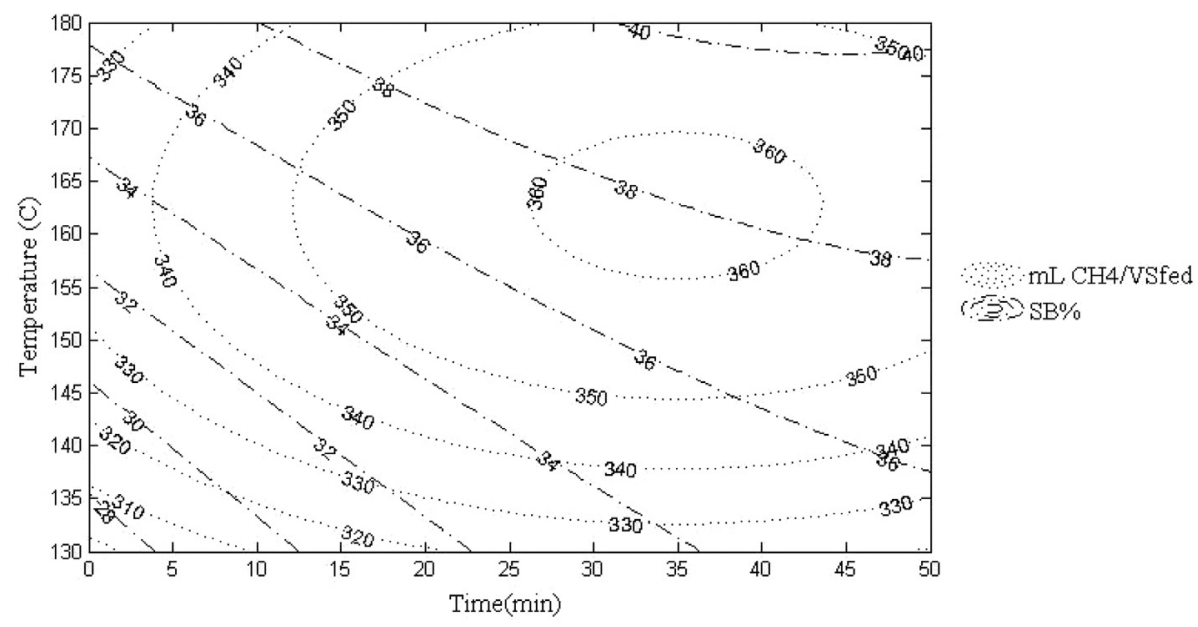

Fig. 6. Superimposed contour plots for methane production and solubilisation. 
solubilisation of $41 \%$ was achieved at higher operation conditions $\left(180^{\circ} \mathrm{C}, 49 \mathrm{~min}\right.$ and $1 \mathrm{flash}$ ). The increase of WAS solubilisation and parallel decrease on methane production at high pre-treatment temperature and long times, indicate that some soluble but nonbiodegradable compounds were produced during severe thermal pre-treatment. This is probably because of the production of melanoidins, as reported by many studies (Ariunbaatar et al., 2014; Xue et al., 2015).

Third, similar thermal hydrolysis efficiency (more than 50\%) could be obtained working at a wider process conditions: at 140-170 ${ }^{\circ} \mathrm{C}$ for $5-35 \mathrm{~min}$ respectively. These results are very interesting in order to minimize energy requirement of thermal hydrolysis process.

Finally, surface plots and contour plots for sludge solubilisation (Fig. 3) and methane production (Fig. 5) can be equated in order to compare the trend and optimal values for temperature and time. The contour plot curves of solubilisation and methane production were superimposed (Fig. 6) to exhibit that there is no joint optimum thermal hydrolysis conditions for both variables.

From Fig. 6 it can be clearly concluded that there is no common peak for both variables, meaning that thermal hydrolysis conditions for solubilisation do not correspond to maximum methane production. This conclusion approves that solubilisation is not a trustworthy parameter for thermal hydrolysis productivity.

The translation of these results from a practical point of view is that the solubilisation measurement is not a suitable prediction parameter to quantify thermal hydrolysis efficiency. The increase in solubilisation obtained at high intensity pre-treatment is not always associated with increase in methane production.

\section{Conclusions}

Thermal hydrolysis of waste activated sludge is a robust pretreatment, leading to significant improvements in anaerobic digestion (up to $70 \%$ increases in methane production) operating in a wide range of experimental conditions. The key mechanisms and variables of the process are: heating (temperature and time) and decompression mechanism (slow or steam explosion). The statistical analysis performed exhibited that efficiency of the pretreatment is mainly influenced by temperature, while the reaction time has a lower incidence. And there is no direct correlation between the solubilisation achieved and the methane production increase. While solubility increases sharply at high intensity pretreatment (high temperature and long times), the methane production presents an optimum, that when exceeded, recalcitrant compounds may appear. Consequently, it is not recommended the use of solubilisation as a prediction parameter to quantify pretreatment efficiency, since it is not related to methane production.

An increase in methane production exceeding $50 \%$ was obtained by a steam explosion pre-treatment performed in the range $140-170{ }^{\circ} \mathrm{C}$ heating and 5-35 min. Therefore, an exhaustive control of thermal pre-treatment conditions appears to be not necessary, while the selection of operation conditions play a key role on the process economics.

\section{References}

Angelidaki, I., Alves, M., Bolzonella, D., Borzacconi, L., Campos, J.L., Guwy, A.J. Kalyuzhnyi, S., Jenicek, P., Van Lier, J.B., 2009. Defining the biomethane potential (BMP) of solid organic wastes and energy crops: a proposed protocol for batch assays. Water Sci. Technol. 59 (5), 927-934.

Appels, L., Degreve, J., Van der Bruggen, B., Van Impe, J., Dewil, R., 2010. Influence of low temperature thermal pre-treatment on sludge solubilisation, heavy metal reléase and anaerobic digestion. Bioresour. Technol. 101, 5743-5748.

Appels, L., Baeyens, J., Degreve, J., Dewil, R., 2008. Principles and potential of the anaerobic digestion of waste activated sludge. Prog. Energy Combust. Sci. 34, 755-781.

Ariunbaatar, J., Panico, A., Esposito, G., Pirozzi, F., Lens, P.N.L., 2014. Pretreatment methods to enhance anaerobic digestion of organic solid. Appl. Energy 123, $143-156$.

Benito-Roman, O., Alonso, E., Cocero, M.J., 2013. Ultrasound-assisted extraction of $\beta$ glucans from barley. LWT - Food Sci. Technol. 50, 57-63.

Bougrier, C., Delgenès, J.P., Carrère, H., 2008. Effects of thermal treatments on five different waste activated sludge samples solubilisation, physical properties and anaerobic digestion. Chem. Eng. J. 139 (2), 236-244.

Bup Nde, D., Abi, C.F., Tenin, D., Kapseu, C., Tchiegang, C., 2012. Optimisation of the cooking process of sheanut kernels (Vitellaria paradoxa Gaertn.) using the doehlert experimental design. Food Bioprocess Technol. 5, 108-117.

Cano, R., Pérez-Elvira, S.I., Fdz-Polanco, F., 2015. Energy feasibility study of sludge pretreatments: a review. Appl. Energy 149, 176-185.

Dwyer, J., Starrenburg, D., Tait, S., Barr, K., Batstone, D.J., Lant, P., 2008. Decreasing activated sludge thermal hydrolysis temperature reduces product colour, without decreasing degradability. Water Res. 42 (18), 4699-4704.

Elliot, A., Mahmood, T., 2012. Comparison of mechanical pretreatment methods for the enhancement of anaerobic digestion of pulp paper waste. Water Sci. Technol. 84, 497-505.

Fernández-Polanco, F., Velázquez, R., Pérez-Elvira, S.I., Casas, C., Del Barrio, D. Cantero, F.J., Fernández-Polanco, M., Rodríguez, P., Panizo, L., Serrat, J., Rouge, P., 2008. Continuous thermal hydrolysis and energy integration in sludge anaerobic digestion plants. Water Sci. Technol. 57 (8), 1221-1226.

Garrido, J.M., Fdz-Polanco, M., Fdz-Polanco, F., 2013. Working with energy and mass balances: a conceptual framework to understand the limits of municipal wastewater treatment. Water Sci. Technol. 67, 2094-2301.

Hii, K., Baroutina, S., Parthasarathy, R., Gapes, D.J., Eshtiaghi, N., 2014. A review of wet air oxidation and thermal hydrolysis technologies. Bioresour. Technol. 155, 289-299.

Jung, K.W., Hwang, M.J., Cha, M.J., Ahn, K.H., 2015. Application and optimization of electric field-assisted ultrasonication for disintegration of waste activated sludge using response surface methodology with a Box-Behnken design. Ultrason. Sonochem. 22, 437-445.

Kim, D., Lee, K., Park, K.Y., 2015. Enhancement of biogas production from anaerobic digestion of waste activated sludge by hydrothermal pretreatment. Int. Biodeterior. Biodegrad. 101, 42-46.

Pérez-Elvira, S.I., Fdz-Polanco, F., Fdz-Polanco, M., Rodríguez, P., Rougé, P., 2008. Hydrothermal multivariable approach: full-scale feasibility study. Electron. J. Biotechnol. 11, 7-8.

Sarat Chandra, T., Suvidha, G., Mukherji, S., Chauhan, V.S., Vidyashankar, S., Krishnamurthi, K., Sarada, R., Mudliar, S.N., 2014. Statistical optimization of thermal pretreatment conditions for enhanced biomethane production from defatted algal biomass. Bioresour. Technol. 162, 157-165.

Seongyeob, J., Sukyoung, J., SoonWoong, C., 2014. Enhancement of anaerobic biodegradability and solubilization by thermal pre-treatment of waste activated sludge. New Renew. Energy 10, 20-29.

Xue, Y., Liu, H., Chen, S., Dichtl, N., Dai, X., Li, N., 2015. Effects of thermal hydrolysis on organic matter solubilisation and anaerobic digestion of high solid sludge. Chem. Eng. J. 264, 174-180.

Zhang, L., Zhang, Y., Zhang, Q., Verpoort, F., Cheng, W., Caoi, L., Li, M., 2014. Sludge gas production capabilities under various operational conditions of the sludge thermal hydrolysis pretreatment process. J. Energy Inst. 87, 121-126.

Zhang, S., Guo, H., Du, L., Liang, J., Lu, X., Li, N., Zhang, K., 2015. Influence of $\mathrm{NaOH}$ and thermal pretreatment on dewatered activated sludge solubilisation and subsequent anaerobic digestion: focused on high-solid state. Bioresour. Technol. 185, 171-177. 